\title{
Tackling the habitat fragmentation panchreston
}

\author{
David B. Lindenmayer and Joern Fischer
}

Centre for Resource \& Environmental Studies, The Australian National University, Canberra, ACT 0200, Australia

The term 'habitat fragmentation' is often used inconsistently and as a broad umbrella for many patterns and processes that accompany landscape change. This has made it a panchreston or an explanation or theory used in such a variety of ways as to become meaningless. The panchreston problem has hampered efforts to understand and mitigate the negative impacts of habitat fragmentation on biodiversity, and has contributed to several largely unproductive debates. To overcome the panchreston problem, we suggest that the focus of future work needs to be specified more clearly within several key themes that comprise the broad domain of habitat fragmentation. Here, we outline three of these key themes and provide unambiguous terminology to help overcome the panchreston problem.

\section{Introduction}

Biodiversity loss is a major part of global change [1], with some researchers forecasting even greater future losses than occurred during past mass extinction events [2]. Key factors negatively impacting biodiversity include land-use intensification [3] and habitat fragmentation [4,5]. The term 'habitat fragmentation' is widely used as an umbrella term for many ecological processes, patterns of vegetation cover, and biotic responses that accompany alteration of landscapes by humans. A recent review of the areas published by conservation biologists found habitat fragmentation to be a massive topic and the largest single area of study in conservation biology [6]. Despite such an enormous research effort, we believe that progress in conservation-related fragmentation research has been too slow, given current rates of landscape alteration and species loss.

Often 'habitat fragmentation' is used so broadly that it has become vague and ambiguous, thereby limiting its practical value for conservation managers [7,8]. Bunnell [9] labelled the term 'habitat fragmentation' a panchreston, which is 'an explanation or theory...made to fit all cases, being used in such a variety of ways as to become meaningless' [10]. The word 'panchreston' originates from ancient Greek, where its meaning was 'good for everything' [10]. Here, we highlight the nature of the habitat fragmentation panchreston, demonstrate why it is a significant problem and propose solutions to improve our conservation of biodiversity. In addition, some of these solutions might be more generally applicable in a range of other fields of

Corresponding author: Lindenmayer, D.B. (davidl@cres.anu.edu.au).

Available online 4 December 2006. ecology and conservation science, such as restoration ecology and population biology.

\section{The panchreston problem}

Habitat fragmentation produces a wide range of effects across several spatial scales and levels of biological organization. It can alter many different ecological processes, change spatial patterns of vegetation cover in landscapes and influence individual species and assemblages of taxa. Such complexity is reflected by the frequent use of habitat fragmentation as an umbrella term. An ISI Web of Science (http://portal.isiknowledge.com/portal.cgi) search of papers published between 2001 and 2005 in three journals devoted to biodiversity conservation (Conservation Biology, Biological Conservation and Biodiversity and Conservation) found 79 papers with the term 'habitat fragmentation' in the abstract. Our analysis of these papers revealed that the use of the term implied different themes in different papers. At a single-species level, the focus of papers was on habitat isolation (Table $1 ; 14$ papers), habitat subdivision (12 papers), and habitat area (six papers). At the level of spatial vegetation patterns, papers focused on vegetation area (12 papers), vegetation subdivision (11 papers), vegetation isolation (five papers), edge effects (three papers) and vegetation degradation (one paper).

Many papers used the term 'habitat fragmentation' in a way that implied at least two and often more of these themes. By far the most common use of the phrase was as a generic umbrella term for many themes (46 papers), which is why the number of papers in the different classifications adds to more than 79. Thus, 'habitat fragmentation' has come to mean many different things to different people and has lumped under it many interacting processes and spatial patterns that accompany human landscape modification. These are suggested to have complex negative effects on individual species and entire assemblages of species.

\section{Consequences of the panchreston problem}

Because habitat fragmentation is dynamic and complex, many diverse perspectives on it are to be expected [11]. However, the loose, vague and often inconsistent application of 'habitat fragmentation' in the ecological and conservation biology literature has had some important negative consequences.

\section{Contributing to largely unproductive debates}

First, the inconsistent application of the term 'habitat fragmentation' has contributed to several debates that 
Table 1. Key themes and associated terms for use in studies of the impacts of landscape change on biodiversity

\begin{tabular}{|c|c|}
\hline Theme and term & Definition \\
\hline \multicolumn{2}{|c|}{ Biological organization and perspective } \\
\hline $\begin{array}{l}\text { Species perspective of a } \\
\text { modified landscape }\end{array}$ & $\begin{array}{l}\text { Perception of a landscape by a given (non-human) species; important features include sources of food and } \\
\text { shelter, and appropriate climatic conditions }{ }^{a}\end{array}$ \\
\hline $\begin{array}{l}\text { Human perspective of a } \\
\text { modified landscape }\end{array}$ & $\begin{array}{l}\text { Perception of a landscape by humans; features include patches of different types of land cover and their spatial } \\
\text { arrangement (including native vegetation) }^{b}\end{array}$ \\
\hline \multicolumn{2}{|l|}{ Land cover and habitat } \\
\hline \multicolumn{2}{|l|}{ Species perspective } \\
\hline Habitat & The resources and conditions present in an area that produce occupancy for a particular species ${ }^{c}$ \\
\hline Habitat loss & $\begin{array}{l}\text { Loss of habitat for a given species from an area, precluding that taxon from persisting there; viz the area } \\
\text { becomes nonhabitat for that species }\end{array}$ \\
\hline Habitat degradation & $\begin{array}{l}\text { The reduction in quality or condition of an area of habitat for a given species, thereby impairing the } \\
\text { demographics of individuals or populations of that species }{ }^{c}\end{array}$ \\
\hline Habitat sub-division & Breaking apart of a large area of habitat into several smaller areas \\
\hline \multicolumn{2}{|l|}{ Human perspective } \\
\hline Native vegetation & The cover of vegetation occurring in an area prior to human landscape modification \\
\hline Native vegetation loss & Removal of native vegetation (e.g. through land clearing) \\
\hline $\begin{array}{l}\text { Native vegetation } \\
\text { deterioration }\end{array}$ & $\begin{array}{l}\text { Reduction in the condition of native vegetation (e.g. relative to a specified benchmark for particular structural } \\
\text { features) }\end{array}$ \\
\hline Vegetation sub-division & Breaking apart of a single large area of vegetation into several smaller areas \\
\hline \multicolumn{2}{|l|}{ Connectivity } \\
\hline \multicolumn{2}{|l|}{ Species perspective } \\
\hline Habitat connectivity & Functional linkages between habitat patches for a given species: a species-specific entity \\
\hline Habitat isolation & $\begin{array}{l}\text { Functional separation of habitat patches for a given species: a species-specific entity and the opposite of habitat } \\
\text { connectivity }\end{array}$ \\
\hline \multicolumn{2}{|r|}{ 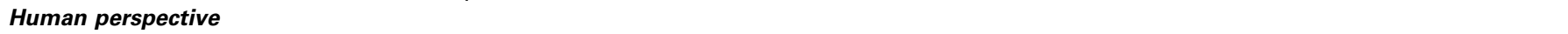 } \\
\hline Landscape connectivity & Physical linkage of areas of native vegetation cover within a landscape \\
\hline Vegetation isolation & Physical separation of patches of vegetation: the opposite of landscape connectivity \\
\hline Ecological connectivity & $\begin{array}{l}\text { Functional linkages of ecological processes at multiple spatial scales (e.g. trophic relationships, disturbance } \\
\text { processes and hydroecological flows) }\end{array}$ \\
\hline
\end{tabular}

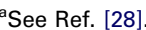

${ }^{b}$ See Ref. [29]

'See Ref. [16].

${ }^{\mathrm{d}}$ See Ref. [49].

have been largely unproductive. This is, in part, based on: (i) many concepts being universally agreed as being important (e.g. connectivity) but being too broadly conceived, thereby rending them difficult to use in practice; and (ii) different workers arguing at cross purposes using different interpretations of terms [12-15]. Conservation biologists and ecologists need to be precise and consistent in their use of concepts and terms to communicate effectively with each other and colleagues from other disciplines [16]. Such problems of mis-communication are magnified when there are public policy and legal implications of ecological work. An example is that of the conservation of the Northern Spotted Owl in north-western North America and the associated legal and policy controversies in the 1990s these surrounded the habitat requirements of the species, the maintenance of viable populations, ways to promote successful dispersal, the impacts of old growth logging, and forest reservation $[17,18]$.

\section{Ignoring the need for careful separation}

A second consequence of the panchreston problem has been that, although many patterns and processes associated with habitat fragmentation are interrelated [19], the need to separate them carefully has often been overlooked. Such separation is crucial to identify and quantify the underlying mechanisms threatening species and ecosystems. As an example, many studies do not distinguish between the effects of habitat loss and habitat isolation, even though they are fundamentally different processes [20] that each have unique impacts. Often one pattern (e.g. the spatial distribution of a species or set of species) is correlated with another pattern (e.g. the spatial distribution of patches of native vegetation), with limited ability to tease apart the ecological processes linking the two patterns.

Without a focus on the mechanisms giving rise to emergent patterns (Box 1), much of the existing 'habitat fragmentation' literature has become dominated by 'storytelling' of case studies describing species-specific or landscape-specific findings, which are difficult to generalize to other taxa or locations [21,22], thus thwarting attempts to identify 'clear insights into system dynamics' [23]. An example is that of the declining Australian woodland bird, the speckled warbler Chthonicola sagittata. One study, focussing on patches of remnant vegetation but ignoring their vegetation structure, concluded that large patches were crucial for maintaining the species [24]. Conversely, another investigation in the same geographical area and conducted simultaneously, found that the speckled warbler bred successfully in small but structurally complex revegetation plantings (S. Bond, Honours Thesis, The Australian National University, 2004).

\section{Effectiveness of mitigation attempts}

A third consequence of the panchreston problem (which is directly related to the second) is that attempts to mitigate the impacts of landscape change on biodiversity might not be as effective as they could otherwise be. It is an ecological truism that identification of key threatening processes is fundamental to devising strategies to mitigate those threats [25] (Box 1). Strategies to counter impacts will 
Box 1. Tackling the fragmentation panchreston and 'unfragmenting' a rare bird species

The endangered eastern bristlebird Dasyornis brachypterus has been the target of extensive field studies at Booderee National Park on the south coast of New South Wales (south-eastern Australia) for many years $[54,55]$. The focus has been on a single species (within the biological organization theme) and its habitat requirements (within the land-cover theme). Early work established strong relationships between two patterns: (i) the spatial distribution of the bird; and (ii) the spatial distribution of patches of complex multilayered heathland and other vegetation types with high levels of understorey cover. Thus, there was early recognition that habitat and native vegetation cover were not synonymous.

Wildfire was considered to be an important factor influencing the distribution of the eastern bristlebird, but recent collaborative studies between The Australian National University and the Department of Environment and Heritage (http://cres.anu.edu.au/ $\mathrm{dbl} / \mathrm{jbstudy}$.php) have indicated that the species makes full post-fire recovery within three years of a burn. The key threatening process has been found to be predation by the exotic red fox Vulpes vulpes, which formerly confined the eastern bristlebird to dense areas of vegetation that were inaccessible to foxes. An intensive and extensive poison-baiting program targeted at foxes over the past four years has significantly reduced populations of these introduced predators. As a result, populations of the eastern bristlebird have now expanded and occupy a greater range of vegetation types across Booderee National Park. What was formerly a 'fragmented' population confined to patches with particular structural attributes has become an 'unfragmented' population. The work on the eastern bristlebird highlights the crucial importance of clearly defining the focus of a given study to explain observed patterns effectively via an underlying ecological process and to then guide conservation management strategies.

vary depending upon which process is the primary threat to a given species or assemblage. The panchreston problem might make it difficult to identify such primary threats effectively. As an example, if habitat loss is the main threat, then increasing the size of individual patches of remaining habitat might be the most effective conservation management option [26]. By contrast, if habitat subdivision and the resulting habitat isolation are the key problems for a species, then strategies to link habitat patches or establish stepping stones to promote natural dispersal, or strategies to facilitate 'artificial dispersal' through translocation programs, might be appropriate management options [27].

\section{Tackling the panchreston problem}

Clarity might be improved if it is recognized that the domain of habitat fragmentation is comprised of several broad themes or axes of work. Three major axes are: (i) biological organization; (ii) land cover; and (iii) connectivity. The clear specification of where the focus of a particular study or mitigation strategy lies along the continuum encompassed by these themes will be aided by the precise and consistent use of terms. Varying uses of concepts and terms have arisen, in part, through different research traditions and approaches in fields such as landscape ecology, which often focus on spatial patterns in vegetation cover, compared with an emphasis on single species and their habitat requirements, which often dominates disciplines such as population biology. Nevertheless, a clearer conceptual framework combined with unambiguous terminology, with ecologists and conservation biologists speaking the same language, should make it possible to:

- Better focus new research and make it more effective (through better problem framing, separation of different processes and improved understanding of the processes that give rise to emergent patterns).

- Speed progress toward the development of strategies that can best mitigate the negative impacts of landscape modification on biodiversity (e.g. Box 1).

- Limit the potential for unproductive debates about theories and concepts.

There might also be other benefits, such as the facilitation of more rigorous reviews of past research to identify general principles that go beyond species- and landscape-specific outcomes.

\section{Biological organization and perspective}

Biological organization and perspective is our first theme within the broad domain of habitat fragmentation. Biological organization refers to whether the focus is on a single species or an aggregate measure for multiple taxa (e.g. species richness or assemblage composition). Perspective corresponds to whether the focus is the perception of a landscape by a single taxon [28] or a human perspective of a landscape for multiple species [29]. Specifying the focus of work is important because research approaches and impact mitigation strategies derived for one species might not be suitable for other species [30]; likewise, approaches that target broad assemblages might not be suitable for a given species of interest. Several debates have been fuelled, in part, by confusion over perspective and the level of biological organization in question. Examples include: (i) whether methods such as the focal species approach (sensu Ref. [31]) that are based on a single species can be an effective multi-species surrogate for landscape restoration $[32,33]$; and (ii) whether the concept of thresholds in the amount of habitat for single species [34] can be extrapolated validly to thresholds in vegetation cover in explaining responses in species richness and other aggregate measures [35-38].

\section{Land cover and habitat}

The theme of land cover and habitat is closely related to the first theme of biological organization and perspective. It requires researchers to specify whether the focus of work is on either land-cover patterns in a landscape (e.g. amount and configuration of vegetation) or on patterns of habitat suitable for a particular individual species (e.g. particular trees for a hollow-dependent animal species [39]). Failure to specify the focus has created significant problems. For example, Debinski and Holt [40] reviewed fragmentation experiments and found that, in contrast to theory, species richness did not always decrease with 'habitat' loss and subdivision. This was partly because, for some species, areas outside the pre-defined 'habitat patches' were in fact suitable habitat. Such apparent contradictions arise because some authors use 'habitat' to mean native vegetation or wilderness [41], whereas others define it with a specific organism in mind [34].

Thus, although the term 'habitat' is often used loosely [16] as equivalent to 'native vegetation', its precise 
meaning should be (after Ref. [16]) 'the resources and conditions present in an area that produce occupancy' for a particular species, population or individual. Because habitat is a species-specific entity (Table 1), habitat loss is also a species-specific entity. Habitat loss is not always synonymous with native vegetation clearing because a landscape extensively altered by humans where vegetation loss has been substantial might effectively experience little or no loss of habitat for some species (e.g. the galah Cacatua roseicapilla in the extensively cleared wheatbelt of Western Australia [42]). Conversely, a landscape supporting a complete cover of native vegetation might contain no habitat for some species (e.g. because of a lack of naturally suitable environmental conditions or limited structural features, such as old-growth forest stands [43]). The distinction between habitat loss and loss of native vegetation cover is crucial because some species can survive in modified landscapes. Thus, production areas should not be considered non-habitat for such species [44].

\section{Connectivity}

Connectivity is a highly controversial topic that is the subject of many debates, such as: (i) the role of corridors and their importance for particular species versus their value for assemblages and ecological processes [12-15]; and (ii) the appropriate definition and measurement of connectivity for species, landscapes and ecosystems. For example, Tischendorf and Fahrig [45] consider connectivity to be a landscape-scale concept, whereas Moilanen and Hanski [46] argue that it is better understood as a patchscale concept. Although both groups of authors agree that connectivity is organism specific, Soulé et al. [47] argue that connectivity should be seen more broadly to encompass processes such as trophic relations, hydroecological flows and the spread of natural disturbances.

Within the connectivity theme, we believe a careful distinction is required between connectivity of habitat for an individual species, connectivity of human-defined patterns of land cover and connectedness of ecological processes. To highlight such distinctions, the term 'habitat connectivity' should reflect the connectedness of habitat patches for a given taxon (Table 1). Because the notion of a 'landscape' is a human construct [48], we argue that the term 'landscape connectivity' should relate to the physical connectedness of patches of native vegetation cover as perceived by humans. The term 'ecological connectivity' [47] should reflect the connectedness of ecological processes at multiple spatial scales (Table 1; [49]). Ecological connectivity can be difficult to measure, but it has been quantified in recent studies [50,51].

Although the three connectivity concepts are interrelated, they are not synonymous. Under some circumstances, habitat connectivity and landscape connectivity will be similar [50]. In other cases, what constitutes habitat connectivity from the perspective of a given species will be different from the human perspective of landscape connectivity [28].

\section{Relationship between the themes}

We recognize that the themes we have described are strongly interrelated. For example, where a species is the unit of biological organization, land cover is best examined in relation to 'habitat' cover for the species (as opposed to the cover of native vegetation) and connectivity is best examined in relation to habitat connectivity for the species (Table 1). We also recognize that the themes are continua and that the terms that we apply to signify focal areas of work correspond to nodes along these continua. Nevertheless, the approach to breaking the broad domain of habitat fragmentation into subcomponent themes is necessary to help tackle the panchreston problem. Without this approach, we believe that there is little hope that existing confusion can be overcome. It will remain difficult to identify ecological mechanisms [40], ecologists will carry on speaking different languages, debates about concepts such as connectivity will persist $[14,15,46]$ and ascertaining the effectiveness of alternative conservation strategies will continue to be difficult [52].

\section{Improving future work on habitat fragmentation}

Based on our conceptual framework of the broad domains of habitat fragmentation and associated terminology, an approach to tackling the habitat fragmentation panchreston can be seen as a series of logically linked steps (Figure 1). These steps (Figure 1) can be framed as a sequence of questions: which themes in the habitat fragmentation domain are to be examined? What processes and patterns within these themes are the key ones to investigate (e.g. habitat loss, habitat subdivision or landscape connectivity)? What is the response being quantified: the presence or abundance of a particular species, the reproductive success of that species, or an aggregate measure such as species richness? Which patterns and processes associated with landscape change might give rise to the patterns of abundance, breeding success or assemblage composition that are being documented and how can they be quantified? What is the appropriate conceptual landscape model that forms the backdrop against which particular hypotheses might be tested? Is the island model appropriate [7] or should the landscape be conceptualised as a series of species-specific habitat gradients [28,53]? Which methods are appropriate for examining the problems most in need of testing? Given a particular research outcome, what might be the best management strategies to mitigate the key negative problems stemming from landscape alteration? Is mitigation successful and can monitoring provide useful new insights for future work?

Although these questions or reasonable facsimiles of them might sound trite, our experience has indicated they are rarely explicitly considered in many studies of landscape change. However, posing them as part of tackling the habitat fragmentation panchreston should aid the development of strategies to better mitigate the negative impacts of landscape modification on biodiversity. Notably, the approach outlined here and summarized in Figure 1 could equally apply to several areas of applied ecological research beyond habitat fragmentation. Reintroduction biology and restoration ecology are two of many. Increasing the rate of progress in these and other fields will be crucial for slowing rates of biodiversity loss and promoting natural resource management practices that are more ecologically sustainable in the medium- to long-term. 


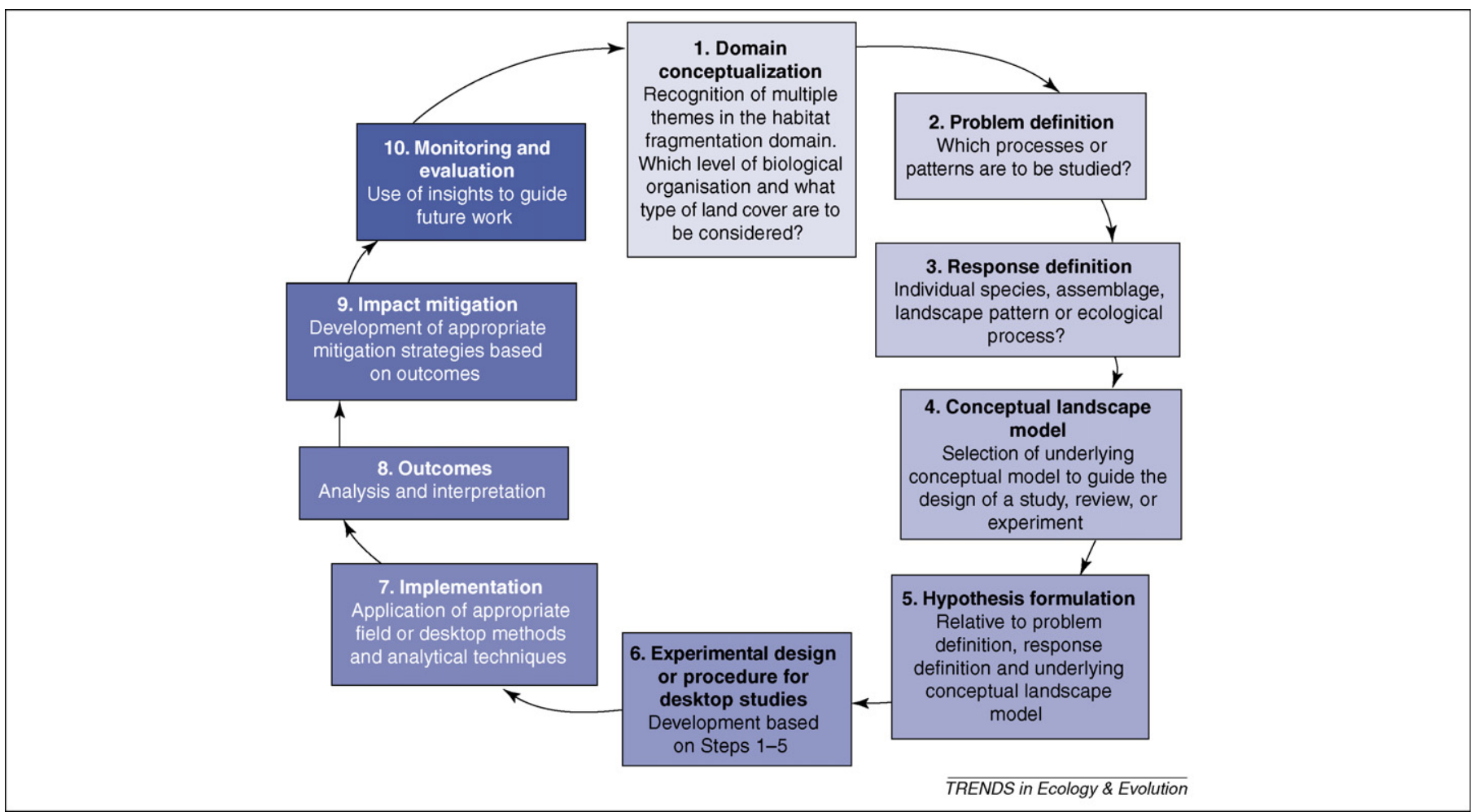

Figure 1. Steps to guide research to deal with the habitat fragmentation panchreston and to develop strategies to better mitigate the impacts of habitat fragmentation.

\section{Acknowledgements}

We are grateful for funding from the Australian Research Council, Land and Water Australia, and the Kendall Foundation. Comments from A. Felton, and three referees greatly helped to improve an earlier version of this article.

\section{References}

1 Sala, O.E. et al. (2000) Global biodiversity scenarios for the year 2100. Science 287, 1770-1774

2 Ward, P. (2004) The father of mass extinctions. Conserv. Pract. 5, 12-19

3 Foley, J.A. et al. (2005) Global consequences of land use. Science 309, 570-574

4 Saunders, D.A. et al. (1991) Biological consequences of ecosystem fragmentation: a review. Conserv. Biol. 5, 18-32

5 Primack, R. (2001) The causes of extinction. In Encyclopedia of Biodiversity (Levin, S.A., ed.), pp. 697-713, Academic Press

6 Fazey, I. et al. (2005) What do conservation biologists publish? Biol. Conserv. 124, 63-73

7 Haila, Y. (2002) A conceptual genealogy of fragmentation research: from island biogeography to landscape ecology. Ecol. Appl. 12, 321-334

8 Regan, H.M. et al. (2002) A taxonomy and treatment of uncertainty for ecology and conservation biology. Ecol. Appl. 12, 618-628

9 Bunnell, F.L. (1999) Let's kill a panchreston: giving fragmentation meaning. In Forest Fragmentation - Wildlife and Management Implications (Rochelle, J.A. et al., eds), pp. vii-xiii, Brill

10 Oxford University Press (2005) Oxford English Dictionary, Oxford University Press

11 Groom, M.J. et al., eds (2005) Principles of Conservation Biology (3rd edn), Sinauer Associates

12 Noss, R.F. and Beier, P. (2000) Arguing over little things: response to Haddad et al. Conserv. Biol. 14, 1546-1548

13 Noss, R.F. (1987) Corridors in real landscapes: a reply to Simberloff and Cox. Conserv. Biol. 1, 159-164

14 Haddad, N.M. et al. (2000) On experimentation and the study of corridors: response to Beier and Noss. Conserv. Biol. 14, 1543-1545

15 Simberloff, D.A. et al. (1992) Movement corridors: conservation bargains or poor investments? Conserv. Biol. 6, 493-504

16 Hall, L.S. et al. (1997) The habitat concept and a plea for standard terminology. Wildl. Soc. Bull. 25, 173-182
17 Murphy, D.D. and Noon, B.R. (1992) Integrating scientific methods with habitat conservation planning: reserve design for northern spotted owls. Ecol. Appl. 2, 3-17

18 Forest Ecosystem Management Assessment Team (1993) Forest Ecosystem Management: An Ecological, Economic and Social Assessment, USDA Forest Service

19 Crome, F.H. (1994) Tropical rainforest fragmentation: some conceptual and methodological issues. In Conservation Biology in Australia and Oceania (Moritz, C. and Kikkawa, J., eds), pp. 61-76, Surrey Beatty \& Sons

20 Fahrig, L. (2003) Effects of habitat fragmentation on biodiversity. Annu. Rev. Ecol. Evol. Syst. 34, 487-515

21 Krebs, C. (1999) Current paradigms of rodent population dynamics what are we missing? In Ecologically-Based Management of Rodent Pests (Singleton, G.R. et al., eds), pp. 33-48, Australian Centre for International Agricultural Research

22 Shrader-Frechette, K.S. and McCoy, E.D. (1993) Method in Ecology. Strategies for Conservation, Cambridge University Press

23 Bissonette, J.A. and Storch, I. (2002) Fragmentation: is the message clear? Conserv. Ecol. 6, 14 (http://www.consecol.org/vol16/iss12/art14)

24 Gardner, J.L. (2004) Winter flocking behaviour of speckled warblers and the Allee effect. Biol. Conserv. 118, 195-204

25 Caughley, G. and Gunn, A. (1996) Conservation Biology in Theory and Practice, Blackwell Science

26 McCarthy, M.A. and Lindenmayer, D.B. (1999) Incorporating metapopulation dynamics of Greater Gliders into reserve design in disturbed landscapes. Ecology 80, 651-667

27 Cooper, C.B. et al. (2002) Effects of remnant size and connectivity on the response of brown treecreepers to habitat fragmentation. Emu 102, $249-256$

28 Manning, A.D. et al. (2004) Continua and Umwelt: novel perspectives on viewing landscapes. Oikos 104, 621-628

29 McIntyre, S. and Hobbs, R. (1999) A framework for conceptualizing human effects on landscapes and its relevance to management and research models. Conserv. Biol. 13, 1282-1292

30 Simberloff, D. Individual species management: threatened taxa and invasive species. In Managing and Designing Landscapes for Conservation: Moving from Perspectives to Principles (Lindenmayer, D.B. and Hobbs, R.J., eds), Blackwell Publishing (in press) 
31 Lambeck, R.J. (1997) Focal species: a multi-species umbrella for nature conservation. Conserv. Biol. 11, 849-856

32 Lambeck, R.J. (2002) Focal species and restoration ecology: response to Lindenmayer et al. Conserv. Biol. 16, 549-551

33 Lindenmayer, D.B. et al. (2002) The focal-species approach and landscape restoration: a critique. Conserv. Biol. 16, 338-345

34 Homan, R.N. et al. (2004) Critical thresholds associated with habitat loss for two vernal pool-breeding amphibians. Ecol. Appl. 14, 15471553

35 Andrén, H. (1994) Effects of habitat fragmentation on birds and mammals in landscapes with different proportions of suitable habitat - a review. Oikos 71, 355-366

36 Mönkkönnen, M. and Reunanen, P. (1999) On critical thresholds in landscape connectivity: a management perspective. Oikos 84, 302-305

37 Radford, J.Q. and Bennett, A.F. (2004) Thresholds in landscape parameters: occurrence of the white-browed treecreeper Climacteris affinis in Victoria, Australia. Biol. Conserv. 117, 375-391

38 Lindenmayer, D.B. et al. (2005) Vegetation cover thresholds and species responses. Biol. Conserv. 124, 311-316

39 Lindenmayer, D.B. et al. (1995) A method for predicting the spatial distribution of arboreal marsupials. Wildl. Res. 22, 445-456

40 Debinski, D.M. and Holt, R.D. (2000) A survey and overview of habitat fragmentation experiments. Conserv. Biol. 14, 342-355

41 Kerr, J.T. and Deguise, I. (2004) Habitat loss and the limits to endangered species recovery. Ecol. Lett. 7, 1163-1169

42 Saunders, D.A. and Ingram, J. (1995) Birds of Southwestern Australia: An Atlas of Changes in Distribution and Abundance of the Wheatbelt Fauna, Surrey Beatty \& Sons
43 Marcot, B.G. (1997) Biodiversity of old forests of the west: a lesson from our elders. In Creating a Forestry for the 21st Century (Kohm, K.A. and Franklin, J.F., eds), pp. 87-105, Island Press

44 Daily, G.C. (2001) Ecological forecasts. Nature 411, 245

45 Tischendorf, L. and Fahrig, L. (2000) On the usage and measurement of landscape connectivity. Oikos 90, 7-19

46 Moilanen, A. and Hanski, I. (2001) On the use of connectivity measures in spatial ecology. Oikos 95, 147-151

47 Soulé, M.E. et al. (2004) The role of connectivity in Australian conservation. Pac. Conserv. Biol. 10, 266-279

48 Haila, Y. and Dyke, C., eds (2006) How Nature Speaks. The Dynamics of the Human Ecological Condition, Duke University Press

49 Fischer, J. and Lindenmayer, D.B. Landscape modification and habitat fragmentation: a synthesis. Glob. Ecol. Biogeogr. (in press)

50 Levey, D.J. et al. (2005) Effects of landscape corridors on seed dispersal by birds. Science 309, 146-148

51 Cascante, A. et al. (2002) Effects of dry tropical forest fragmentation on the reproductive success and genetic structure of the tree Samanea saman. Conserv. Biol. 16, 137-147

52 Beier, P. and Noss, R.F. (1998) Do habitat corridors provide connectivity? Conserv. Biol. 12, 1241-1252

53 Fischer, J. et al. (2004) Appreciating ecological complexity: habitat contours as a conceptual landscape model. Conserv. Biol. 18, 12451253

54 Baker, J. (1997) The decline, response to fire, status and management of the eastern bristlebird. Pac. Conserv. Biol. 3, 235-243

55 Baker, J.R. (2000) The Eastern Bristlebird: cover dependent and fire sensitive. Emu 100, 286-298

\section{Have you contributed to an Elsevier publication? Did you know that you are entitled to a $30 \%$ discount on books?}

A $30 \%$ discount is available to all Elsevier book and journal contributors when ordering books or stand-alone CD-ROMs directly from us.

To take advantage of your discount:

1. Choose your book(s) from www.elsevier.com or www.books.elsevier.com

\section{Place your order}

Americas:

Phone: +18007824927 for US customers

Phone: +18004603110 for Canada, South and Central America customers

Fax: +1 3144534898

author.contributor@elsevier.com

All other countries:

Phone: $+44(0) 1865474010$

Fax: $+44(0) 1865474011$

directorders@elsevier.com

You'll need to provide the name of the Elsevier book or journal to which you have contributed. Shipping is free on prepaid orders within the US.

If you are faxing your order, please enclose a copy of this page.

\section{Make your payment}

This discount is only available on prepaid orders. Please note that this offer does not apply to multi-volume reference works or Elsevier Health Sciences products.

For more information, visit www.books.elsevier.com 